\title{
BMJ Global Health Combating the COVID-19 infodemic: a three-level approach for low and middle-income countries
}

\author{
Sambit Dash, ${ }^{1}$ Ateeb Ahmad Parray (D) , ${ }^{2}$ Loren De Freitas (D) , ${ }^{3}$ \\ Md Imran Hossain Mithu, ${ }^{4}$ Md Mustafizur Rahman (D) , ${ }^{5}$ Aarthy Ramasamy, ${ }^{6}$ \\ Apurva Kumar Pandya (1) ${ }^{7}$
}

To cite: Dash S, Parray AA, De Freitas L, et al. Combating the COVID-19 infodemic: a three-level approach for low and middle-income countries. BMJ Global Health 2021;6:e004671. doi:10.1136/ bmjgh-2020-004671

Received 6 December 2020 Revised 25 December 2020 Accepted 6 January 2021

Check for updates

C Author(s) (or their employer(s)) 2021. Re-use permitted under CC BY-NC. No commercial re-use. See rights and permissions. Published by BMJ.

For numbered affiliations see end of article.

Correspondence to Ateeb Ahmad Parray; ahmad.ateeb101@gmail.com

\section{INTRODUCTION}

The COVID-19 crisis has contributed to the development of an 'infodemic' that hinders an adequate public health approach to managing the crisis. The WHO defines an infodemic as an 'overabundance of information-some accurate and some notthat occurs during an epidemic'. ${ }^{1}$ Fake news, propaganda and conspiracy theories, ubiquitous in the era of social media, have spread since the beginning of the COVID-19 pandemic. Reports suggest that a rumour is three times more likely to be spread in social media than accurate information. ${ }^{2}$ This is of great concern as it often leads to reduced trust in health institutions and services and impedes the evidence-informed approach in managing the pandemic. The infodemic may also promote hate speech and associated stigmatisation which may contribute to exclusions of vulnerable sections of society.

The adverse effects of the infodemic may be exacerbated in low and middle-income countries (LMICs) where low health literacy levels, poor health infrastructure and poor resource settings exist. One example is the spread of misinformation that concentrated alcohol can kill the novel coronavirus. This led to methanol poisoning that contributed to the deaths of more than 700 people in Iran and resulted in blindness in 60 people in other LMICs. ${ }^{3}$ Misperceptions about COVID-19 also entail less adherence with proven precautionary behaviours such as social distancing interventions. ${ }^{4}$ Broad categories of misinformation related to COVID-19 include those about the disease itself, conspiracy theories, scapegoating and false cures. A concerted, tailor-made, evidence-informed effort from a transdisciplinary perspective is required to address the impact of the infodemic in LMICs. In this article, we suggest measures
Summary box

- The COVID-19 crisis has contributed to the development of an 'infodemic' that hinders an adequate public health approach to managing the crisis.

- The adverse effects of the infodemic may be exacerbated in low and middle-income countries (LMICS) where low health literacy levels, poor health infrastructure and poor resource settings exist.

- In order to manage the COVID-19 infodemic in LMICs, a three-level approach is suggested in the context of countering fake news.

- Public health communicators may benefit from using unique methods such as story-telling to understand the underlying factors that promote infodemics as well as explore practical tools that can counter the tide of misinformation.

- Laws in LMICs to address privacy concerns in the use of data and personal health information are weak and concerted efforts need to be made to strengthen them.

and approaches that LMICs can undertake in order to combat the COVID-19 infodemic and future infodemics.

\section{A MULTIPRONGED APPROACH}

In order to manage the COVID-19 infodemic in LMICs, a three-level approach is suggested (table 1). This approach was proposed by Haciyakupoglu et al in the context of countering fake news. ${ }^{5}$ We have modified the existing framework to fit the COVID-19 infodemic. The approach includes pre-emptive, immediate and long-term measures as described in the following sections.

\section{Pre-emptive measures}

Once the infodemic attains enormous proportions, it becomes difficult to control. Therefore, the first step should be preventing the infodemic from occurring or limiting its 
Table 1 A multipronged approach to deal with infodemics

\begin{tabular}{llll}
\hline Time frame & Pre-emptive measures & Immediate measures & Long-term measures \\
\hline Measures & Prepare & Establish & Promote health literacy \\
Develop definitions & Surveillance & Dovelop \\
Clarify roles & Synthesise & Curriculum on fake news \\
& Educate & Evidence & Public health awareness \\
Inform public & Informed policymaking & campaigns \\
Train public & Capacities of existing & resources \\
Communicate & Decentralise & Legislations \\
Establish collaborations & Involve communities & Leverage role models \\
Monitor information & Target the vulnerable & Digital technology & Pact checking and rumour \\
& detection applications & Partnerships with social \\
& media giants & Establish a reliable platform \\
& for sharing information
\end{tabular}

spread as soon as it appears. This entails the development of clear definitions of relevant terms such as infodemic, fake news and misinformation. Such clarity would enable countries to determine the agencies required to manage the infodemic, clarify their roles, enhance communication strategies and identify events that can create an infodemic flare. Establishing collaborations at governmental levels as well as with non-government bodies both at a regional and global level would also be useful. Such alliances would result in knowledge sharing and conveying a consistent response. Iran, which was hard hit by COVID19, had an unprecedented public-private partnership when private hospitals, $20 \%$ of all hospitals, shared facilities and equipment with their government counterparts. ${ }^{6}$

Another measure is to educate the public on the disease epidemic itself using clear, simple, jargon-free language. Lay summaries of scientific evidence should be provided for the public. ${ }^{7}$ An example of such a measure is WHO's Information Network for Epidemics, ${ }^{8}$ which provides resources and regular updates, answering pertinent questions as epidemics unfold. It aims to debunk myths that emerge on social media and other sources and leverage existing networks within sectors to disseminate information. Alongside this, it would be beneficial to train and educate the general population on ways to recognise misinformation and fake news. ${ }^{9}$ Together, these measures should assist in limiting the spread of misinformation.

The actions and communication by political leaders may impact a country's ability to manage an infodemic effectively. In LMICs with lower trust in governments and weak state capacity, cooperative relationships need to be established by political leadership which can promote solidarity and enable resources exchange for satisfying both the short and long-term responses to infodemic. Confidence-building measures to build trust in governments to provide information as early and as often as possible in a crisis (and enable the amplification of, and action is taken from this advice) need to be undertaken.
At the same time, algorithmic transparency, information governance and quality assurance for robust and trusted communication and information services should be instilled to check for misinformation. ${ }^{10}$ Ministerial teams, task forces and legislative committees that can work year-round can undertake pre-emptive measures when necessary.

\section{Immediate measures}

Leveraging technology for monitoring and overall strengthening of the infodemic response should be considered in LMIC contexts. ${ }^{11}$ Establishing systematic monitoring, disease surveillance and evaluation system as well as promoting scientific research using robust methodologies and tools can inform existing infodemic or design responsive interventions and generate evidence for policymaking. Promotion of collective learning through the formation of communities of practice for regular sharing of experiences, knowledge and best practices is called for.

Evidence synthesis and informed policymaking is one avenue that may assist in reducing the burden associated with the COVID-19 infodemic. ${ }^{12} 13$ In LMICs, the evolving pandemic, limited resources, and economic and political pressure create a challenging atmosphere to promote evidence-informed policymaking. Despite these challenges, LMICs should focus on generating their own research, led by local researchers. ${ }^{14}$ Focusing on local voices, their beliefs and misconceptions, what they want and why may contribute to increased trust and confidence in the local health systems and governments. Research findings should be used to develop policies grounded in local, contextual research. Communities should also be included and used to build and guide policymaking. Ultimately, these actions will strengthen capacity and build resilience in the countries. To add to it, leaders, decision makers and policymakers in LMICs should be part of global consortiums generating high-quality research in 
order to stay abreast with worldwide research and guidelines, tailoring these to their own individual contexts.

Promoting role models (such as celebrities, local leaders, teachers, community health workers (CHW)) for preventing misinformation can be vital. Many countries have been establishing hotlines and other mechanisms through which the public can access correct information and discuss their concerns. ${ }^{15}$

Equity-informed infodemic response should be of paramount importance. Risk communication targeting vulnerable and marginalised populations for protecting and preventing ill effects of infodemic is critical. ${ }^{16}$ Outreach interventions should target (with government schemes/aid) marginalised populations such as women, rural and informal settlement dwellers, refugee/migrant populations and nomadic tribes.

As immediate measures, digital technology advancements can be leveraged for establishing rumour detection, a certification system for fact checking such as rumour detector, a health alert on WhatsApp and a chatbot on Facebook Messenger. ${ }^{17}$ Downranking ads for essential limited medical supplies, such as face masks, to prevent hoarding and flag companies that allow fake advertising news may curb the infodemic. For example, Facebook temporarily banned ads for medical face masks to avoid coronavirus exploitation. ${ }^{18}$ LMICs should seek partnerships with social media giants (such as Facebook, Twitter, Google, Instagram, and so on) to assist with monitoring misleading information about COVID-19, provide access to reliable information and promote responsible roles of social media platforms. ${ }^{10}$

\section{Long term}

LMICs should focus on promoting health literacy in the long term. Health literacy is defined as the "cognitive and social skills which determine the motivation and ability of individuals to gain access to, understand and use information in ways which promote and maintain good health'. ${ }^{15}$ Improving health literacy rates at an individual, community and population level empowers persons to make informed decisions, and this, in turn, may reduce the spread of misinformation. ${ }^{919}$ Designing public campaigns for preventing fake news and promoting healthy digital habits are needed. For example, educating high school students on identifying fake news, highlighting fake news on social media devices, promoting rumour reporting and encouraging the use of accurate information. ${ }^{19}$

Another long-term measure is to embed infodemiology education into school and university curriculums. This may range from incorporating 'how to spot fake news' to the basics of public health modules in school education to the creation of citizen-systematic reviewers in older adults, as suggested by Chrousos and Mentis. ${ }^{19}$ These measures may result in a well-informed citizenry capable of countering infodemics in future. Moreover, universities should be encouraged to establish chairs in the field of infodemiology while fostering fellowships for public health and communication professionals. ${ }^{19}$
CHWs are the backbone of health systems in LMICs. With low access to smartphones and the internet in some LMICs, CHWs are an essential link between the communities and the public health system. Training CHWs on fact checking and effective communication can be a crucial community-level strategy for preventing rumours and improving access to accurate information. ${ }^{20} \mathrm{CHWs}$ assist with providing accurate information to communities and contribute to improving health literacy, building public trust and helping with sociobehavioural research. The Government of India and its state governments have enhanced the health insurance coverage and provided special incentives to CHWs while facilitating them with recognition of their services. ${ }^{21}$ However, while imparting this responsibility, it is invariably essential to ensure this activity does not overburden them or perceive this as an additional task to be reported.

Legislation to facilitate an evidence-informed, expertdriven timely infodemic response should not be underestimated. Legislation may prove beneficial in five areas-technology infrastructure, information management and data privacy, provision of fines or punishments for breach of regulations, access to technology (priority setting, inclusiveness and equity) and ethical standards. ${ }^{22}$ However, since often the state capacity is low in LMICs, legislative measures should be less preferred to nonlegislative actions.

\section{CHALLENGES AND FUTURE DIRECTION}

While the above measures provide a structured response to manage the COVID-19 in LMICs, there are numerous inherent challenges in combating the infodemic that needs addressing for the above approaches to be practical.

Considering populations with poor access to education, widespread inequity, marginalised communities and indigenous people, promoting health literacy could be challenging. Public health communicators may benefit from using unique methods such as story-telling as well as adapting the message to consider cultural and contextual factors and linking with common cultural practices. ${ }^{23}$ Thus, research activities should focus on understanding the underlying factors that promote infodemics as well as exploring practical tools that can counter the tide of misinformation.

Evidence-informed policymaking can be challenging in LMICs as a result of a lack of standard research methodologies and weak research capacity. Initiatives like WHO's evidence-informed policy network ${ }^{24}$ and VERIFIED $^{25}$-an intervention by the United Nations-bring together policymakers, researchers and civil society that can be replicated at both national and federal level or smaller administrative units.

While big data analytics using machine learning and artificial intelligence look promising for infoveillance, privacy concerns of individuals and communities are paramount. Laws in LMICs to address privacy concerns 
in the use of data and personal health information are often weak, and special attention needs to be paid to strengthen them.

Imposing fines for spreading rumour and fake news, along with the imposition of sanction on media outlets, could have the unintended consequence of stifling media freedom in that garb. It is a reality that cannot be ignored and thus while punitive action may be warranted in certain cases, capacity building should trump the former.

Health systems in LMICs are often fragile and underresourced. Managing the infodemic in LMICs is crucial both at an individual and population level to ensure compliance with public health measures. This, in turn, will contribute to reducing the burden of care on fragile health systems.

\section{CONCLUSION}

Health systems in LMICs are often vulnerable and underresourced. Managing the infodemic in LMICs is crucial both at an individual and population level to ensure compliance with public health measures and thus reduce the burden of care. The three-level approach outlined in this paper is a proposed strategy that decision and policy makers in LMICs may use as a guide when tackling the COVID-19 infodemic and infodemics generally. A host of tools including educational interventions, partnering with social media giants, training CHWs and legislative measures need to be employed in a well-planned multipronged manner to manage an infodemic. Engaging and empowering local communities as well as understanding what factors contribute to misinformation, rumours and mistrust is essential when executing the strategy.

\section{Author affiliations}

${ }^{1}$ Department of Biochemistry, Manipal Academy of Higher Education, Manipal, Karnataka, India

${ }^{2}$ Center of Excellence for Gender, Sexual and Reproductive Health and Rights, BRAC University James P Grant School of Public Health, Dhaka, Dhaka District, Bangladesh

${ }^{3}$ North Central Regional Health Authority, Champ Fleurs, Trinidad and Tobago ${ }^{4}$ BRAC University James P Grant School of Public Health, Dhaka, Dhaka District, Bangladesh

${ }^{5}$ Sher-e-Bangla Medical College, University of Dhaka, Barisal, Bangladesh ${ }^{6}$ Diabetology, Madras Diabetes Research Foundation, Chennai, Tamil Nadu, India ${ }^{7}$ Indian Institute of Public Health Gandhinagar, Gandhinagar, Gujarat, India

Twitter Ateeb Ahmad Parray @AteebParray, Md Imran Hossain Mithu @imran_ imran2020, Aarthy Ramasamy @aarthu28 and Apurva Kumar Pandya @apurva_b_ pandya

Acknowledgements The Health Systems Global's Technical Working Groups (HSG TWG) - SHAPES, Teaching and Learning (T\&L) and Quality in Universal Health and Healthcare-acted as platforms for expressing interest in, and facilitating collaboration on this piece. We acknowledge the contribution to background discussions on the issues from the members of aforementioned HSG's TWGs.

Contributors SD conceived the idea of the article. SD, AAP and AKP initiated a draft of key conceptual points to which all authors input and which was used to prepare an early draft. LDF provided case examples from different country contexts. All authors made text input to iterative drafts and provided reference materials using shared online document editing software. AAP coordinated the inputs and edited the final manuscript. The final version of the article was approved by all the authors.
Funding The authors have not declared a specific grant for this research from any funding agency in the public, commercial or not-for-profit sectors.

Competing interests None declared.

Patient consent for publication Not required.

Provenance and peer review Not commissioned; internally peer reviewed.

Data availability statement There are no data in this work.

Open access This is an open access article distributed in accordance with the Creative Commons Attribution Non Commercial (CC BY-NC 4.0) license, which permits others to distribute, remix, adapt, build upon this work non-commercially, and license their derivative works on different terms, provided the original work is properly cited, appropriate credit is given, any changes made indicated, and the use is non-commercial. See: http://creativecommons.org/licenses/by-nc/4.0/.

\section{ORCID iDs}

Ateeb Ahmad Parray http://orcid.org/0000-0002-1653-1856

Loren De Freitas http://orcid.org/0000-0002-8431-5311

Md Mustafizur Rahman http://orcid.org/0000-0002-6496-703X

Apurva Kumar Pandya http://orcid.org/0000-0003-0178-3978

\section{REFERENCES}

1 World Health Organization. Infodemic Management - Infodemiology. World Heal Organ 2020 https://www.who.int/teams/riskcommunication/infodemic-management

2 Sommariva S, Vamos C, Mantzarlis A, et al. Spreading the (fake) news: exploring health messages on social media and the implications for health professionals using a case study. Am J Health Educ 2018;49:246-55.

3 Islam MS, Sarkar T, Khan SH, et al. COVID-19-Related infodemic and its impact on public health: a global social media analysis. Am J Trop Med Hyg 2020;103:1621-9.

4 Bridgman A, Merkley E, Loewen PJ, et al. The causes and consequences of COVID-19 misperceptions: understanding the role of news and social media. HKS Misinfo Review 2020;1.

5 Haciyakupoglu G, Hui JY, Suguna VS. Countering fake news a survey of recent global initiatives. Singapore, 2018. https://www.rsis.edu.sg/ wp-content/uploads/2018/03/PR180416_Countering-Fake-News.pdf

6 Seddighi H, Seddighi S, Salmani I, et al. Public-Private-People partnerships (4P) for improving the response to COVID-19 in Iran. Disaster Med Public Health Prep 2020:1-6.

7 Tangcharoensathien V, Calleja N, Nguyen T, et al. Framework for managing the COVID-19 infodemic: methods and results of an online, crowdsourced who technical consultation. J Med Internet Res 2020;22:e19659.

8 World Health Organization. WHO's Information Network for Epidemics: EPI-WIN. World Heal Organ 2020 https://www.who.int/ teams/risk-communication

9 Naeem SB, Bhatti R, Khan A. An exploration of how fake news is taking over social media and putting public health at risk. Health Info Libr J 2020;12320. doi:10.1111/hir.12320. [Epub ahead of print: 12 Jul 2020].

10 Limaye RJ, Sauer M, Ali J, et al. Building trust while influencing online COVID-19 content in the social media world. Lancet Digit Health 2020;2:e277-8.

11 Sezgin E, Huang Y, Ramtekkar U, et al. Readiness for voice assistants to support healthcare delivery during a health crisis and pandemic. NPJ Digit Med 2020;3:122.

12 Yang K. What can COVID-19 tell us about evidence-based management? Am Rev Public Adm 2020;50:706-12.

13 Stewart R, El-Harakeh A, Cherian SA, et al. Evidence synthesis communities in low-income and middle-income countries and the COVID-19 response. Lancet 2020;396:1539-41.

14 Gupta M, Wahl B, Adhikari B, et al. The need for COVID-19 research in low- and middle-income countries. Glob Health Res Policy 2020:5:33

15 Sørensen K, Van den Broucke S, Fullam J, et al. Health literacy and public health: a systematic review and integration of definitions and models. BMC Public Health 2012;12:80.

16 Smith JA, Judd J. COVID-19: vulnerability and the power of privilege in a pandemic. Health Promot J Austral 2020;31:158-60.

17 Ofrin RH, Buddha N, Htike MM, et al. Strengthening risk communication systems for public health emergencies in the who south-east Asia region. WHO South East Asia J Public Health 2020;9:15-20. 
18 Lyons K. Facebook temporarily bans ads for medical face masks to prevent coronavirus exploitation. The Verge, 2020. Available: https:// www.theverge.com/2020/3/7/21169109/facebook-instagram-bansads-face-masks-coronavirus [Accessed 6 Nov 2020].

19 Chrousos GP, Mentis A-FA. Medical misinformation in mass and social media: an urgent call for action, especially during epidemics. Eur J Clin Invest 2020;50:e13227.

20 Bhaumik S, Moola S, Tyagi J, et al. Community health workers for pandemic response: a rapid evidence synthesis. BMJ Glob Health 2020;5:e002769.

21 Nanda P, Lewis TN, Das P, et al. From the frontlines to centre stage: resilience of frontline health workers in the context of COVID-19. Sex Reprod Heal Matters 2020;28:1837413-8.
22 Ahinkorah BO, Ameyaw EK, Hagan JE, et al. Rising above misinformation or fake news in Africa: another strategy to control COVID-19 spread. Front Commun 2020;5:45.

23 Pang T. For innovation-driven public health, facts outweigh opinions. Nat Med 2020;26:160-2.

24 WHO. Evidence-Informed policy network. World Heal Organ 2019 http://www.who.int/evidence/en/

25 Wone A. Verified: un launches new global initiative to combat misinformation. Africa Renew, 2020. Available: https://www.un. org/africarenewal/news/coronavirus/covid-19-united-nationslaunches-global-initiative-combat-misinformation [Accessed $4 \mathrm{Nov}$ 2020]. 